\title{
Contralateral pulmonary metastases in lung cancer
}

\author{
W ILSON I. B. ONUIGBO \\ Department of Pathology, General Hospital, Enugu, Nigeria
}

\begin{abstract}
Onuigbo, W. I. B. (1974). Thorax, 29, 132-133. Contralateral pulmonary metastases in lung cancer. It has long been known that lung cancer may attack many organs and yet spare the opposite lung. In 100 cases of this tumour studied at necropsy, only 22 showed contralateral pulmonary spread. Contralateral deposits are generally small and may be related to damaged tissues. Although tissue unsuitability is supposed to underlie the limitation of metastases in recipient organs, this does not apply to the contralateral lung. Since lung tissue is readily accessible to bloodborne cancer cells, research should be directed towards explaining the paradoxical paucity of the metastases.
\end{abstract}

The infrequent spread of lung cancer to the contralateral lung is one of the remarkable features of this tumour. Long ago, Schuster (1929) spoke of the 'extraordinary' way in which a large fungating tumour of one lung can spread to every other organ of the body and yet 'leave the opposite lung completely free from direct or indirect spread.' More recently, Budinger (1958) called it 'the seeming reluctance of this tumor to involve the opposite lung.'

Unfortunately, as Hinson (1958) has stated, some reports on lung cancer metastases do not even mention spread to the lungs themselves, but Muir (1960) recorded contralateral metastases in $20 \%$ of necropsies.

The object of this paper is to present a personal series obtained in Glasgow between 1960 and 1962 inclusive. Emphasis will be placed on those features which characterize growths that successfully invade the contralateral lung.

\section{METHODS}

Necropsies were carried out by the author in 100 cases of lung cancer using the mono-block formalinfixation method described previously (Onuigbo, 1963). The topography of secondary deposits in the contralateral lung was noted carefully and compared with the appearances in the ipsilateral lung.

\section{RESULTS}

Twenty-two out of the 100 cases revealed tumour deposits in the contralateral lung.

Three distribution patterns were discernible thus:
(1) wholly parenchymal deposits

(2) wholly subpleural deposits

11 cases

(3) mixed parenchymal and subpleural deposits

7 cases

In 4 out of the 11 parenchymal cases, the deposits were close to damaged areas of the lung. In one case, the single deposit found contralaterally was situated in an area of healed tuberculosis. In another case, contralateral spread was confined to the upper lobe where there were a few small deposits, as well as a $2 \mathrm{~cm}$ diameter deposit, in a fibrosed area below an emphysematous bulla. The other two cases showed lower lobe growths which had metastasized to areas of emphysema and scarring in both upper lobes.

The largest deposits in the contralateral lung were much smaller than their ipsilateral counterparts in every case and measured not more than $2 \mathrm{~cm}$ across. Most deposits, especially those in the subpleural position, attained only a few millimetres in diameter. There was thus a tendency towards gradation in the size of the deposits across the lungs.

The sequential nature of contralateral spread was deducible from the incidence of deposits attached to the pleura. Not a single case had deposits confined to the contralateral pleura. Seven cases exhibited bilateral involvement. Ten cases revealed deposits in the ipsilateral pleura alone. Such ipsilateral involvement varied from the whole surface being carpeted with innumerable discrete and confluent deposits to there being only a single subpleural deposit.

There was no association between contralateral involvement and invasion of major blood vessels. 
Thus, in each of the three cases which I reported elsewhere (Onuigbo, 1972), tumour tissue was propagated as far as the cavity of the left atrium and yet no deposits were detected in the contralateral lung.

\section{DISCUSSION}

My data confirm Budinger's (1958) view that contralateral lung deposits are characteristically small sized. This feature may assist in differentiating between pulmopulmonary spread and spread from extrapulmonary sources.

The data also support Spencer's (1962) opinion that secondary cancer may show a predilection for growing in the vicinity of damaged lung tissue. This phenomenon may be due to alterations in the tissues or in the circulation. The circulatory changes may be lymphogenous or haematogenous. Both routes deserve equal consideration for, as Lilienthal (1925) appreciated, either of them may be responsible for the formation of discrete deposits in the pulmonary parenchyma.

Clearly, owing to its unique venous connexions, lung cancer is able to shower any organ with malignant emboli. Spencer (1962) considered that actual metastasis from such showers is limited only by unsuitability of the tissues of the recipient organ. However, does tissue unsuitability also apply in the case of the contralateral lung? No. The frequently observed invasion of the ipsilateral lung amply testifies to the suitability of lung tissue as soil for nourishing lung cancer cells.

The infrequency of metastases in the contralateral lung contrasts sharply with its many opportunities for receiving blood-borne emboli. First, since blood is completely mixed in the aorta (McDonald, 1960), this channel transports to the contralateral lung through its bronchial branches a definite proportion of metastasizing cells present in each stroke volume of the heart. These bronchial branches supply not only the bronchi but also the lungs, carrying to them a hundredth part of the total cardiac output (Harris and Heath, 1962). A second route is the vertebral venous plexus (Batson, 1940). Third, of all the blood draining back to the right heart from every invaded organ, half must be distributed to the contralateral lung. Lastly, this incoming blood even brings in previously lymph-borne tumour cells which travel up the thoracic duct (Onuigbo, 1967).
Thus, with regard to the contralateral lung, it has been established not only that many vascular routes are available for lung cancer cells but also that its tissues are suitable for their growth. Therefore, the paucity of metastases in this lung calls in question the effectiveness of those bloodborne invaders which arrive there.

Future research should be directed towards solving the problem of the fate of those bloodborne lung cancer cells which reach the contralateral lung. It seems to me that in such research it may prove useful to make some use of the contralateral trend recognized to occur in the cervical lymph nodes in lung cancer (Onuigbo, 1962; le Roux, 1968).

I wish to thank Emeritus Professor D. F. Cappell, who provided the facilities for collecting the original records. For their help in furnishing duplicates after the Nigerian Civil War I am indebted to Professor J. R. Anderson and Drs. A. M. Chambers, A. T. Sandison, J. F. Boyd, Mary Catto, G. B. M. Clarke, and $\mathbf{R}$. R. Wilson.

\section{REFERENCES}

Batson, O. V. (1940). The function of the vertebral veins and their role in the spread of metastases. Annals of Surgery, 112, 138.

Budinger, J. M. (1958). Untreated bronchogenic carcinoma. Cancer (Philadelphia), 11, 106.

Harris, P. and Heath, D. (1962). The Human Pulmonary Circulation, p. 326. Livingstone, Edinburgh.

Hinson, K. F. W. (1958). The spread of carcinoma of the lung. In Carcinoma of the Lung, edited by J. R. Bignall, vol. 1, p. 140. Livingstone, Edinburgh.

le Roux, B. T. (1968). Bronchial Carcinoma, p. 95. Livingstone, Edinburgh.

Lilienthal, H. (1925). Thoracic Surgery, vol. 2, p. 292. Saunders, Philadelphia.

McDonald, D. A. (1960). Blood Flow in Arteries, pp. 58 and 67. Arnold, London.

Muir, C. S. (1960). Cancer of the lung, trachea and larynx in Singapore. British Journal of Cancer, 14, 1.

Onuigbo, W. I. B. (1962). Contralateral cervical node metastases in lung cancer. Thorax, 17, 201.

(1963). A mono-block formalin-fixation method for investigating cancer metastasis. Zeitschrift für Krebsforschung, 65, 209.

(1967). The carriage of cancer cells by the thoracic duct. British Journal of Cancer, 21, 496.

(1972). Direct extension of cancer between pulmonary veins and the left atrium. Chest, 63, 444.

Schuster, N. H. (1929). Primary carcinoma of the lung. Journal of State Medicine, 37, 278.

Spencer, H. (1962). Pathology of the Lung, pp. 651 and 668. Pergamon, Oxford. 